\section{Prevalence of Severe Atopic Dermatitis in Adults in 3 Areas of Spain}

Sicras-Mainar A ${ }^{1}$, Navarro-Artieda $\mathrm{R}^{2}$, Sánchez L ${ }^{3}$, Sastre $\mathrm{J}^{4}$ ${ }^{1}$ Red de Investigación en Servicios Sanitarios (Fundación REDISS), Barcelona, Spain

${ }^{2}$ Documentación Médica, Hospital Germans Trias i Pujol, Badalona, Barcelona, Spain

${ }^{3}$ Dirección de Atención Primaria, Avilés, Asturias, Spain

${ }^{4}$ Servicio Alergología, Fundación Jiménez Díaz y Universidad Autónoma de Madrid, Madrid, Spain

J Investig Allergol Clin Immunol 2018; Vol. 28(3): 195-197 doi: 10.18176/jiaci.0234

Key words: Severe atopic dermatitis. Prevalence. Spain.

Palabras clave: Dermatitis atópica grave. Prevalencia. España.

Atopic dermatitis (AD) is a chronic relapsing inflammatory skin disease [1]. It affects $10 \%-20 \%$ of children, the most prevalent form being chronic disease, and $1 \%-3 \%$ of adults, particularly in the most developed Western societies [1-3]. Fifty percent of cases resolve during adolescence, with up to $20 \%$ of cases persisting into adulthood and a prevalence of $1 \%-3 \%$ in patients aged more than 60 years [4].

Available evidence on the prevalence of severe AD is uncertain and scarce at the population level. No studies on the prevalence of AD have focused on Spain. The main goal of this study was to describe the prevalence of severe AD in routine clinical practice at different locations in Spain. As a secondary goal, associated comorbidities and therapeutic approaches were described.

A cross-sectional (prevalence) study was conducted based on a review of medical registries (digital databases, dissociated data). The study population was obtained from health care providers' registries, which were unified in the dissociated database of the RedISS (Red de Investigación en Servicios Sanitarios) Foundation. Data came from the OMIap digital clinical history and other complementary databases. Registries from patients in Asturias, Catalonia, and the Balearic Islands were obtained. Patients who required healthcare services during 2015-2016 were included. The inclusion criteria were age $\geq 18$ years, registered diagnosis of severe AD at least 12 months before the study, inclusion in the prescription program (registered daily dose, timing and duration of each treatment; $\geq 2$ prescriptions during the follow-up period), and ability to guarantee regular follow-up ( $\geq 2$ health registries in the system; at least 1 visit to the dermatology service). The exclusion criteria were change in health center or move outside the study areas, permanent hospitalization, and history of seborrheic dermatitis, contact dermatitis, and/or dyshidrotic eczema.

Registries of patients with AD were obtained from the International Classification of Primary Care in the European Union [5] (codes S87, S88) and/or the International Classification of Disease (Ninth Edition), Clinical Modification
(ICD-9-CM; 691.8, 692.9, 706.8), which include AD, allergic dermatitis, allergic eczema, atopic eczema, atopic neurodermatitis, and xerosis. AD was diagnosed by the physician (reference dermatologist) according to the criteria of Hanifin and Rajka [6] (AD present for over 1 year). AD was considered severe when the patient received an immunosuppressant (cyclosporine, methotrexate, azathioprine, mycophenolate mofetil) or a biologic (omalizumab, rituximab) during followup or had been hospitalized because of AD. Furthermore, administration of systemic corticosteroids and other treatments (immunoglobulins, interferon $\gamma$, hydroxychloroquine, alefacept) received by the patient was registered. Data were obtained from registries of pharmaceutical dispensation and hospital pharmacy services (Anatomical Therapeutic Chemical Classification System) [7]. Age (continuous and by range), sex, and associated comorbidities [5] (Table) were also obtained. Prevalence was calculated as the number of patients diagnosed with AD seen by a dermatologist and treated with immunosuppressants or biologics and/or hospitalized (numerator) divided by the number of individuals assigned to their primary care centers (denominator). Moreover, data were validated to ensure the quality of the results. A descriptive univariate statistical analysis was conducted for variables of interest, and the $95 \%$ confidence intervals (CI) were calculated. A bivariate analysis was conducted with ANOVA and $\chi^{2}$ tests (SPSSWIN, Version 19). Statistical significance was set at $P<.05$ ).

Out of an initial selection of 935894 individuals aged $\geq 18$ years assigned to the centers, 777 patients were included in the study. The prevalence of severe AD in adults was $0.08 \%$ (95\%CI, 0.07-0.09\%) (Table), with mild variability between the different geographical areas analyzed due to a statistical effect with no epidemiological significance. The average time after diagnosis was 29.2 years. The average age was 52.6 years, and $64.5 \%$ of patients were women. Morbidity associated with severe AD was high: arterial hypertension, 37.6\%; dyslipidemia, 29.3\%; asthma, 24.4\%; depression, $21.4 \%$; and allergic rhinitis, $19.4 \%$. In patients with severe $\mathrm{AD}$, the most widely used specific medications were cyclosporine (46.3\%), methotrexate (21.2\%), and mycophenolate mofetil (19.6\%); $1.2 \%$ of patients were hospitalized. Of note, $55.2 \%$ of these patients $(n=777)$ were prescribed systemic corticosteroids. Sociodemographic characteristics, comorbidities, and medication were homogeneous in the individual geographical areas, thus adding consistency to the results. There were no deaths during the follow-up period.

The study results show that the prevalence of severe AD in adults is low in the 3 areas analyzed, thus reinforcing the hypothesis that the high variability in prevalence observed in published data could be due to the quality of registries and the method used to create them. Few observational studies focus on a real-life setting, thus hampering data comparison. Consequently, study results should be interpreted cautiously, particularly when it comes to external validity.

Although data are lacking, the prevalence of severe AD is estimated to be around $5 \%$, whereas that of general AD could be around $2 \%[8,9]$. In a hypothetical and cautious scenario of a general adult prevalence of $2 \%$ for AD and $5 \%$ for severe $\mathrm{AD}$, our results seem to be consistent with these conclusions, even if they are significantly lower. In addition, 
Table. General Characteristics, Comorbidities, and Medication Administered by Geographical Area

\begin{tabular}{|c|c|c|c|c|c|}
\hline Study groups & Asturias & Catalonia & Balearic Islands & Total & $P$ Value \\
\hline Number of patients & 105 & 380 & 292 & 777 & \\
\hline Study population & 124558 & 408377 & 402959 & 935894 & \\
\hline Estimated prevalence, $\%$ & $0.08 \%$ & $0.09 \%$ & $0.07 \%$ & $0.08 \%$ & .001 \\
\hline 95\% Confidence interval & $0.04 \%-0.12 \%$ & $0.07 \%-0.011 \%$ & $0.06 \%-0.08 \%$ & $0.07 \%-0.09 \%$ & \\
\hline \multicolumn{6}{|c|}{ Sociodemographic characteristics } \\
\hline Mean (SD) age, y & $52.6(17.0)$ & $53.4(15.1)$ & $51.7(16.0)$ & $52.6(15.7)$ & .349 \\
\hline Range: $18-44$ years & $32.4 \%$ & $28.4 \%$ & $29.8 \%$ & $29.5 \%$ & \\
\hline 45-64 years & $40.0 \%$ & $43.7 \%$ & $44.5 \%$ & $43.5 \%$ & \\
\hline$\geq 65$ years & $27.6 \%$ & $27.9 \%$ & $25.7 \%$ & $27.0 \%$ & .888 \\
\hline Sex (female) & $63.8 \%$ & $65.3 \%$ & $62.3 \%$ & $64.0 \%$ & .734 \\
\hline Time since diagnosis, years & $30.2(9.3)$ & $28.5(8.3)$ & $29.9(9.0)$ & $29.2(8.7)$ & .044 \\
\hline \multicolumn{6}{|l|}{ Comorbidity } \\
\hline Arterial hypertension & $36.2 \%$ & $39.7 \%$ & $35.3 \%$ & $37.6 \%$ & .472 \\
\hline Diabetes mellitus & $13.3 \%$ & $13.2 \%$ & $10.6 \%$ & $12.2 \%$ & .568 \\
\hline Dyslipidemia & $28.6 \%$ & $28.9 \%$ & $30.1 \%$ & $29.3 \%$ & .929 \\
\hline Obesity & $11.4 \%$ & $19.5 \%$ & $15.1 \%$ & $16.7 \%$ & .093 \\
\hline Active smoking & $16.2 \%$ & $18.4 \%$ & $13.4 \%$ & $16.2 \%$ & .210 \\
\hline Alcoholism & $7.6 \%$ & $5.8 \%$ & $8.6 \%$ & $7.1 \%$ & .371 \\
\hline Ischemic heart disease & $2.9 \%$ & $3.2 \%$ & $1.4 \%$ & $2.4 \%$ & .317 \\
\hline Asthma & $21.0 \%$ & $27.6 \%$ & $21.6 \%$ & $24.5 \%$ & .130 \\
\hline Allergic rhinitis & $19.0 \%$ & $19.7 \%$ & $19.2 \%$ & $19.4 \%$ & .978 \\
\hline Nasal polyposis & $9.5 \%$ & $9.2 \%$ & $7.9 \%$ & $8.8 \%$ & .795 \\
\hline Dementia & $3.8 \%$ & $0.5 \%$ & $1.0 \%$ & $1.2 \%$ & .057 \\
\hline Neuropathy & $6.7 \%$ & $5.0 \%$ & $2.7 \%$ & $4.4 \%$ & .170 \\
\hline Depression & $18.1 \%$ & $23.9 \%$ & $19.2 \%$ & $21.4 \%$ & .222 \\
\hline Anxiety & $15.2 \%$ & $16.3 \%$ & $17.5 \%$ & $16.6 \%$ & .852 \\
\hline Malignant neoplasm & $13.3 \%$ & $13.2 \%$ & $13.0 \%$ & $13.1 \%$ & .996 \\
\hline \multicolumn{6}{|l|}{ Medication administered } \\
\hline Cyclosporine & $49.5 \%$ & $48.9 \%$ & $41.8 \%$ & $46.3 \%$ & .241 \\
\hline Methotrexate & $22.9 \%$ & $19.2 \%$ & $23.3 \%$ & $21.2 \%$ & .400 \\
\hline Azathioprine & $11.4 \%$ & $8.7 \%$ & $10.3 \%$ & $9.7 \%$ & .632 \\
\hline Mycophenolate mofetil & $18.1 \%$ & $19.4 \%$ & $20.9 \%$ & $19.6 \%$ & .634 \\
\hline Omalizumab & $0.0 \%$ & $1.8 \%$ & $3.1 \%$ & $2.0 \%$ & .149 \\
\hline Rituximab & $0.0 \%$ & $2.4 \%$ & $3.4 \%$ & $2.4 \%$ & .148 \\
\hline Patients hospitalized, \% & $1.9 \%$ & $1.6 \%$ & $0.3 \%$ & $1.2 \%$ & .247 \\
\hline \multicolumn{6}{|l|}{ Associated medication } \\
\hline Systemic corticosteroids & $58.1 \%$ & $57.6 \%$ & $51.0 \%$ & $55.2 \%$ & .190 \\
\hline Other drugs & $2.9 \%$ & $5.0 \%$ & $3.1 \%$ & $4.0 \%$ & .369 \\
\hline
\end{tabular}

the waxing and waning nature of the signs and symptoms, the fact that severity is rarely substantially modified for a single patient, and a possible bias in disease classification could, to our understanding, lead us to underestimate severe cases. Considering the comorbidities (Table), our results seem to be in accordance with available data $[2,9,10]$.

The limitations of the present study include a possible bias in patient classification and the therapeutic groups selected, since patients required immunosuppressants. In addition, the number of $\mathrm{AD}$ cases may have been underestimated through under-recording of disease (classification code) or possible variability between patients and professionals. Therefore, it is difficult to generalize our findings.
More studies will be needed to determine the real epidemiology of the disease. Future studies will require assays to improve diagnosis and treatment of $\mathrm{AD}$, as well as to replicate the study. In conclusion, based on the inclusion criteria used in this study, the prevalence of severe $\mathrm{AD}$ in adults is low.

\section{Conflicts of Interest}

A Sicras is an independent consultant who received funding from Sanofi for contributing to this paper.

$\mathrm{J}$ Sastre has received research grants and honoraria for consulting from Sanofi.

The remaining authors declare that they have no conflict of interests. 


\section{Funding}

The study was sponsored by Sanofi.

\section{References}

1. Muraro $A$, Lemanske RF Jr, Hellings PW, Akdis CA, Bieber T, Casale TB, et al. Precision medicine in patients with allergic diseases: Airway diseases and atopic dermatitis-PRACTALL document of the European Academy of Allergy and Clinical Immunology and the American Academy of Allergy, Asthma \& Immunology. J Allergy Clin Immunol. 2016;137:1347-58.

2. Nutten S. Atopic dermatitis: global epidemiology and risk factors. Ann Nutr Metab. 2015;66 Suppl 1:8-16.

3. Silvestre Salvador JF, Romero-Pérez D, Encabo-Durán B. Atopic dermatitis in adults: a diagnostic challenge. J Investig Allergol Clin Immunol. 2017;27(2):78-88.

4. Tanei R, Hasegawa Y. Atopic dermatitis in older adults: A viewpoint from geriatric dermatology. Geriatr Gerontol Int. 2016;16 Suppl 1:75-86.

5. Lamberts $H$, Wood M, Hofmans-Okkes IM (eds). The International Classification of Primary Care in the European Community. With a multi-language layer. Oxford: Oxford University Press, 1993.

6. Hanifin JM, Rajka G. Diagnostic features of atopic eczema. Acta Dermatovenerol Suppl (Stockh). 1980;92:44-7.

7. The Anatomical Therapeutic Chemical Classification System with Defined Daily Doses (ATC/DDD): World Health Organization. Available at: http://www.who.int/classifications latcddd/en/. Accessed: 10/02/2017.

8. Torrelo A1, Ortiz J, Alomar A, Ros S, Pedrosa E, Cuervo J. Health-related quality of life, patient satisfaction, and adherence to treatment in patients with moderate or severe atopic dermatitis on maintenance therapy: the CONDA-SAT study. Actas Dermosifiliogr. 2013;104:409-17.

9. Silverberg Jl. Public Health Burden and Epidemiology of Atopic Dermatitis. Dermatol Clin. 2017;35:283-9.

10. Egeberg A, Andersen YM, Gislason GH, Skov L, Thyssen JP. Prevalence of comorbidity and associated risk factors in adults with atopic dermatitis. Allergy. 2017;72:783-91. 